\title{
A Literature Review of Job Crafting and Its Related Researches
}

\author{
Changyi Peng \\ School of Management, Jinan University, Guangzhou, China \\ Email: 503313491@qq.com
}

How to cite this paper: Peng, C.Y. (2018) A Literature Review of Job Crafting and Its Related Researches. Journal of Human Resource and Sustainability Studies, 6, 1-7. https://doi.org/10.4236/jhrss.2018.61022

Received: January 23, 2018

Accepted: March 17, 2018

Published: March 20, 2018

Copyright (C) 2018 by author and Scientific Research Publishing Inc. This work is licensed under the Creative Commons Attribution International License (CC BY 4.0).

http://creativecommons.org/licenses/by/4.0/

\begin{abstract}
Job crafting is a hot topic in the field of organizational behavior researches and human resource management. Job crafting is a bottom to up behavior, which is different from traditional up to bottom job design, representing the staff's proactivity. Under job crafting, staffs incline to redefine and reshape the job content, working mode and cooperation relationship with teammates. Besides, job crafting can optimize organizational design and working relationship, which improves the staff's working identification and adversity coping ability. Based on the previous research results, this article attempts to summarize the definition, measurement, antecedents and consequences of job crafting. Meanwhile, this article also puts forward future research directions of job crafting.
\end{abstract}

\section{Keywords}

Job Crafting, Job Design, Bottom to up Behavior

\section{Introduction}

With the rapid economic development, people's material living standards continue to improve. For individuals, work has become more than just a means of obtaining material returns, but also an expression of self-worth. More and more people begin to think about the value of their work, and take the initiative to obtain different work meanings and experience through the subjective understanding and practice of the work content and their active interaction with others. This proactive behavior can give full play to the creativity of the employees, and helps the employees realize themselves while benefiting the organization [1]. For example, hairdressers kindly chat with customers to understand the customer requirements for hairstyles, closer to each other's relationship, which is conducive to their own work [2]; the restaurant chef consults guests for sugges- 
tions for dishes while eating, which gives the chef a sense of achievement through preparing elaborate food; hospital cleaners see the work as part of a cure for the patient, to help and serve the patient, or chat with the patient so that the patients can adapt to the hospital environment as quickly as possible [3]. Based on this, Wrzesniewski and Dutton first proposed the concept of "Job Crafting" in 2001 on the basis of summarizing the previous research and explored the proactive working methods from the perspective of employees [3]. The concept is also echoed in the value orientation of Positive Organizational Scholarship (POS) research, with a focus on the positive elements of the organizational environment and the positive results. Job Crafting emphasizes bottom-up behaviors, however, does not reduce the importance of organizational design (top-down), on the contrary, it complements organizational design and enhances employee adaptability.

This article discusses the definition, characteristics, crafting methods and influential factors of job crafting through the commentary on related researches, and hopes to provide readers with a clear research context and future research directions.

\section{Definition and Characteristics of Job Crafting}

\subsection{Definition of Job Crafting}

Job Crafting refers to a series of self-imposed employee behaviors that alter their job tasks and the boundaries of the relationship in order to align their interests, motivations, and passion with the job [3]. Contrary to the top-down design of traditional work, it is the reconstruction of work contents, ways and work relationships by employees on the basis of their formal work design, with the aim of obtaining a sense of work and identity. For example, teachers design innovative teaching programs to enhance students' motivation to learn. Employees in multinational corporation try their best to create a good relationship with their colleagues, superiors and subordinates, though those job are not what they must accomplish. After Wrzesniewski \& Dutton put forward the concept for job crafting, Tims \& Bakker defined job crafting as "For the purpose of balancing job requirement and resources, employees makes change in their behavior according to their ability and needs" [4]. This definition emphasizes the impact of job characteristics on employee motivation and well-being.

In short, no matter in what way to define the job crafting, the essence is that employees take a proactive approach to change the work content and methods to meet the needs of individuals or groups so as to fulfill their work meaning, which is kind of pro-organizational behavior.

\subsection{Characteristics of Job Crafting}

Through the induction of existing research, we can see that the remodeling of work has three typical characteristics, namely, proactiveness, process adaptability and immaterial rewards. 
1) Proactiveness. Job crafting is a reflection of the proactive behavior of employees [5]. Employees with job crafting willing can identify crafting opportunities and actively take action in their work, redefining their tasks and objectives, actively seek resources and opportunities to create favorable conditions for crafting, and actively seek to reshape the challenges [3]. 2) Process adaptability. Research shows that job reshaping cannot happen in one go. It is an ongoing process that may be affected by the employee's career stage [6]. In addition, the process of job crafting is also an adaptive process, and when employees are challenged in the process of crafting, they can use their strengths to solve problems and keep the job going smoothly. 3) Immaterial rewards. Generally, in the career choice or development, employees with job crafting willings not only pursue the material return provided by the work, but also seek to find the intrinsic meaning of the work, such as the realization of personal value, understanding of the world and self-awareness.

\section{Measurement of Job Crafting}

Base on the analysis of existing studies, there are two ways for measure Job crafting.

\subsection{Measurement Based on Task, Cognition and Relationship Crafting}

Based on previous interviews and extensive literature analysis, Wrzesniewski \& Dutton summed up the three types of job crafting [3]. They are task crafting, relationship crafting and cognition crafting, but did not mention the specific measurement methods. Follow-up research mostly relied on previous research and analysis of interviews involved in the literature, qualitative or quantitative development work to reshape the scale or interview, but the lack of standardized measurement methods. For example, to explore the impact of environmental factors at work on job crafting, Ghitulescu conducted job crafting studies on behalf of two different industries and designed different measurement methods of task crafting and relationship crafting [5]. Leana et al. devised six questions to evaluate individual job crafting based on previous literature and information from earlier interviews [7]. In addition, Slemp and Vella-Brodrick developed a job crafting questionnaire based on Leana et al.'s work [8]. In summary, measurement research based on tasks, relationships and cognition crafting has yielded some results and laid a solid foundation for follow-up research.

\subsection{Measurement Based on Job Demands-Resources Model}

Based on job demands-resoureces model, Tims and Bakker divided job crafting into increasing job resources, reducing job and increasing job demands [4]. Subsequently, through exploratory factor analysis, the dimensions of job remodeling are finally defined as increasing the amount of structural working resources, increasing the amount of social working resources, increasing the number of challenging job requirements and reducing the number of obstruc- 
tionist jobs. This four-dimensional model has received widespread support from researchers [9] [10].

\section{Empirical Study on Job Crafting}

\subsection{Antecedent Variables}

Literature studies show that the impact factors to job remodeling is varied. Based on existing literature, this article summarizes the antecedent variables of job crafting into two categories: Individual and environmental factors.

\subsubsection{Individual Factors}

Job crafting is considered as an individual's creative activity. Therefore, it first correlates with personal factors, such as proactive personality, personal motivational orientation, regulatory focus.

1) Proactive personality. Bateman and Crant found that employees with proactive personality traits have less environmental constraints in their work and may exhibit more innovative behaviors [11]. At present, research has shown that employees with active personality traits are more inclined to mobilize their work resources and change job requirements in a positive way so as to change the work environment and working boundaries [12]. 2) Personal motivational orientation. In addition to the fact that proactive personality traits will affect job crafting, personal motivation orientation is also one of the factors that crafting the work [13]. Motivational orientation is divided into intrinsic motivational orientation and extrinsic motivational orientation. Both intrinsic motivational orientation and extrinsic motivational orientation are closely related to the employees' motivation of job crafting [3]. 3) Regulatory focus. Based on regulatory theory, regulatory focus includes promotion focus and prevention focus. Individuals with promotion focus are more likely to embody a strong desire to work and focus on self-growth, and thus are more likely to achieve more satisfaction and achievement by changing their job content. As a result, employees with promotion focus are more responsive to positive outcomes and tend to be more personally satisfied with job crafting [14].

\subsubsection{Environmental Factor}

Environmental factors that affect the job crafting mainly include the degree of environmental monitoring by managers. Wrzesniewski and Dutton argue that discretion, decision latitude and job autonomy in work has strong predictive effect on job crafting, but tight job monitoring may hinder employee job crafting [3]. Supportive organizational climate helps employees to generate positive working attitude and behavior [15]. Parker et al. found that employees who have more autonomy in their work demonstrate a more proactive role-playing experience, more experience in their work, and improved self-awareness and skill levels [16].

\subsection{Outcome Variable}

There are many studies on outcome variables of job crafting. Based on the anal- 
ysis of existing studies, the outcome variables are mainly summarized as three factors. They are meaning of work, work identity and well-being.

1) Meaning of work. Meaning of work refers to the personal understanding of the purpose of their work, or self-value in the work to achieve [17]. Job crafting change the meaning of work mainly through task crafting and relationship crafting, which makes employees feel different work meanings and work purpose changes in the process [3]. 2) Work identity. Work identity is part of job awareness and refers to how individuals define themselves in the organization. Work status is built through the exchange of everyday work and the establishment of relationships and friendships with others. At the same time, people are social and hope to gain others' positive opinions about themselves by interacting with others in their work, that is, building a positive working identity, which not only can help individuals adapt to work and respond to the pressure and challenges in their work, but also to promote the emergence of individual positive behavior. Job crafting helps to achieve the goal of building a positive identity [3]. 3) Employee well-being. When Berg et al. studied how employees experience and pursue unresponsive occupational callings, they found that job remodeling can affect employee well-being [18]. Studies by Tims et al., Slemp and Vella-Brodrick, and Bakker and Demerouti also show that employees can change their work characteristics (such as work resources) to gain happiness through job crafting [12] [19] [20].

\section{Prospect}

Based on the review of the existing research, this article argues that future's job crafting research needs to be further explored in the following aspects.

1) Then impact mechanism of job crafting. Job crafting has a wide range of impact, and most researchers believe that the impact of job crafting is positive, but it remains unclear when and where job crafting will affect employees' attitudes and behaviors. The existence of mediating variables between job remodeling and its impact results has not been explored in the present study and future studies need to be focused on related issues. 2) Comparison of job crafting among Different Groups. In the future, we should make a comparative study of different groups of job crafting methods. For example, what's the difference between duplicated workers and innovative workers to show job crafting? Besides, the future should also carry out a comparative study on the relationship between job crafting and work value orientation.

\section{Conclusion}

In summary, in order to have a better understanding of job crafting and its relative mechanism, this paper clarified the concept of job crafting and presented the main measurement of job crafting. This paper also summarizes the empirical study of job crafting, including its antecedent and outcome variables. By reviewing the empirical study, this paper put forward the research prospect of job 
crafting.

\section{References}

[1] Peter, S. (1990) The Fifth Discipline: The Art and Practice of the Learning Organization. Doubleday Currency, New York, 210-268.

[2] Cohen, R.C. and Sutton, R.I. (1988) Clients as a Source of Enjoyment on the Job: How Hairstylists Shape Demeanor and Personal Disclosures. JAI Press, Greenwish, CT, 1-32.

[3] Wrzesniewski, A. and Dutton, J.E. (2001) Crafting a Job: Revisioning Employees as Active Crafters of Their Work. Academy of Management Review, 25, 179-201.

[4] Tims, M. and Bakker, A.B. (2010) Job Crafting: Towards a New Model of Individual Job Redesign. South African Journal of Industrial Psychology, 36, 1-9. https://doi.org/10.4102/sajip.v36i2.841

[5] Ghitulescu, B.E. (2006) Shaping Tasks and Relationships at Work: Examing the Antecedents and Consequences of Employee Job Crafting. University of Pittsburgh, 30-47.

[6] Organ, D.W. (1988) Organizational Citizenship Behavior: The Good Soldier Syndrome. Lexington Books, Lexington, MA, 79-90.

[7] Leana, C., Appelbaum, E. and Shevchuk, I. (2009) Work Process and Quality of Care in Early Childhood Education: The Role of Job Crafting. Academy of Management Journal, 52, 1169-1192. https://doi.org/10.5465/AMJ.2009.47084651

[8] Slemp, G.R. and Vella-Brodrick, D.A. (2014) Optimizing Employee Mental Health: The Relationship between Intrinsic Need Satisfaction, Job Crafting, and Employee Well-Being. Journal of Happiness Studies, 15, 957-977. https://doi.org/10.1007/s10902-013-9458-3

[9] Petrou, P. (2013) Crafting the Change: The Role of Job Crafting and Regulatory Focus in Adaptation to Organizational Change. Utrechi University, 67-68.

[10] Nielsen, K. and Abildgaard, J.S. (2012) The Development and Validation of a Job Crafting Measure for Use with Blue-Collar Workers. Work and Stress, 26, 365-384. https://doi.org/10.1080/02678373.2012.733543

[11] Bateman, T.S. and Crant, M.J. (1993) The Proactive Component of Organizational Behavior: A Measure and Correlates Summary. Journal of Organizational Behavior, 14, 103-119. https://doi.org/10.1002/job.4030140202

[12] Tims, M., Bakker, A.B. and Derks, D. (2013) The Impact of Job Crafting on Job Demands, Job Resources, and Well-Being. Journal of Occupational Health Psychology, 18, 230-240. https://doi.org/10.1037/a0032141

[13] Amabile, T.M. (1994) The Work Preference Inventory: Assessing Intrinsic and Extrinsic Motivational Orientations. Journal of Personality and Social Psychology, 66, 950-967. https://doi.org/10.1037/0022-3514.66.5.950

[14] Brenninkmeijer, V. and Hekkert-Koning, M. (2015) To Craft or Not to Craft: The Relationships between Regulatory Focus, Job Crafting and Work Outcomes. Career Development International, 20, 147-162. https://doi.org/10.1108/CDI-12-2014-0162

[15] Shanock, L.R. and Eisenberger, E.R. (2006) When Supervisor Feel Supported: Relationship with Subordinates' Perceived Supervisor Support, and Performance. Journal of Applied Psychology, 91, 689-695. https://doi.org/10.1037/0021-9010.91.3.689

[16] Parker, S.K., Wall, T.D. and Jackson, P.R. (1997) That's Not My Job: Developing Flexible Employee Work Orientation. Academy of Management Journal, 40, 899-929. https://doi.org/10.2307/256952 
[17] Brif, A.P. and Nord, W.R. (1990) Meaning of Occupational Work: A Collection of Essays. Lexington Books, Lexington, MA, 33-47.

[18] Berg, J.M., Wrzesniewski, A. and Dutton, J.E. (2010) Perceiving and Responding to Challenges in Job Crafting at Different Ranks: When Proactivity Requires Adaptivity. Journal of Organizational Behavior, 31, 158-186. https://doi.org/10.1002/job.645

[19] Slemp, G.R. and Vella-Brodrick, D.A. (2014) Optimizing Employee Mental Health: The Relationship between Intrinsic Need Satisfaction, Job Crafting, and Employee Well-Being. Journal of Happiness Studies, 15, 957-977. https://doi.org/10.1007/s10902-013-9458-3

[20] Demerouti, E., Bakker, A.B., Nachreiner, F. and Schaufeli, W.B. (2001) The Job Demands-Resources Model of Burnout. Journal of Applied Psychology, 86, 499-512. https://doi.org/10.1037/0021-9010.86.3.499 